\title{
Serological Tests of a Relationship between Rumen Selenomonads in vitro and in vivo
}

\author{
By P. N. HOBSON, S. O. MANN AND W. SMITH \\ Rowett Research Institute, Bucksburn, Aberdeen
}

\begin{abstract}
SUMMARY
Fluorescent antisera to strains of small Selenomonas ruminantium var. lactilyticas grown in vitro from sheep rumen contents appeared to react specifically with some of the large selenomonads seen in vivo in rumen contents. It seems probable, therefore, that the selenomonads isolated by the usual cultural methods are those seen in rumen contents.
\end{abstract}

\section{INTRODUCTION}

In a previous paper (Hobson \& Mann, 1961) the isolation from the sheep rumen of glycerol-fermenting selenomonads, identified as Selenomonas ruminantium var. lactilyticas (Bryant, 1956), was described. These bacteria were isolated by culturing dilutions of rumen fluid from a number of sheep in suitable media. However, the cells which grew in these cultures, although definitely selenomonads in morphology, never exceeded $3 \mu$ in length, and were generally smaller. Direct microscopic observation of rumen contents, however, shows that although there is some variation in size of bacteria morphologically resembling selenomonads, there are usually a number of selenomonads which are very large, being 5-8 $\mu$ in length. These obviously visible large organisms are usually those referred to when mention is made of selenomonads in descriptions of rumen contents (see, for instance, Moir \& Masson, 1952). Although Bryant (1956) reported that some of his strains of $S$. ruminantium isolated from the bovine rumen were up to $7 \mu$ in length in vitro, none of our sheep rumen strains ever attained anything like this size. It is known that cultural conditions can influence the morphology of bacteria, and Herbert (1958) showed that the rate of growth can influence the size of cells of rod-like bacteria (e.g. Aerobacter aerogenes) in continuous culture. It was thought, therefore, that the large selenomonads seen in the rumen, which are growing under presumably optimum conditions in medium in what is, in effect, a continuous culture might be identical with the smaller selenomonads grown in vitro in 'batch' cultures under what might not be completely optimum conditions, and which certainly differ from those obtaining in the living rumen. A possible method of identifying the organisms in vitro and in vivo seemed to be the use of fluorescent antisera. Fluorescent antisera have been used in these laboratories in the study of rumen bacteria for a number of years (e.g. Hobson \& Mann, 1957; Hobson, Mann \& Oxford, 1958) and the necessary apparatus was readily available. This paper describes some results obtained during the experiments. 


\section{METHODS}

Organisms. The isolation and properties of the Selenomonas strains 6 and 17 (from sheep on different diets) were described by Hobson \& Mann (1961), and they had been kept as subcultures on slopes, as described in that paper, since isolation. Strains 6 and 17 were representatives of groups differing slightly in fermentations. The other bacteria used were from stock cultures or formolized suspensions kept in this laboratory, and the properties of many of them have been described in previous papers. We are indebted to Dr M. P. Bryant, U.S.D.A., Beltsville, Maryland, U.S.A., for cultures of bovine rumen strains of Ruminococcus albus, Selenomonas ruminantium (strain GA 192) and $S$. ruminantium var. lactilyticas (strain PC 18).

Preparation of antisera to sheep rumen strains of Selenomonas ruminantium. ' $\mathrm{H}$ ' and ' $\mathrm{O}$ ' antisera were prepared as follows. For ' $\mathrm{O}$ ' antigens cultures were grown for $17 \mathrm{hr}$. in a casitone-yeast liquid medium containing $0.5 \%(\mathrm{w} / \mathrm{v})$ glucose similar in constitution to the media described previously (Hobson \& Mann, 1961). A washed suspension of the cells in saline was heated at $100^{\circ}$ for $2 \mathrm{hr}$., the cells were centrifuged off, washed twice in saline and finally resuspended in saline with $\mathbf{0 . 2 5} \%$ formalin added as preservative. Rabbits were given two courses of six daily intravenous injections of this suspension starting with three injections of $0.2 \mathrm{ml}$. suspension of opacity 1 (opacity tubes, Burroughs Wellcome, Ltd.) and increasing the dose from 0.5 to $1 \mathrm{ml}$. of suspension of opacity 6 during the second week. One week rest was given between the courses, and one week after the final injection the rabbits were bled for preparation of antisera. Starting the injections with a dilute suspension was found necessary since more concentrated suspensions proved fatal in earlier experiments. For testing for ' $O$ ' agglutination alcohol-treated suspensions were prepared by suspending the washed bacteria in $50 \%(\mathrm{v} / \mathrm{v})$ ethanol/saline and keeping at $37^{\circ}$ for $20 \mathrm{hr}$. The bacteria were then centrifuged off and finally suspended in formol-saline as above. For ' $H$ ' antigens cultures were grown for $17 \mathrm{hr}$. in a casitone-yeast medium with the glucose reduced to $0 \cdot 1 \%(w / v)$. Formalin, $\mathbf{0} \cdot 25 \%$ $(\mathrm{v} / \mathrm{v})$ was added to the culture and it was incubated overnight at $37^{\circ}$. The bacteria were centrifuged off and resuspended in $0.25 \%(v / v)$ formol-saline. Antisera were produced by giving rabbits a course of inoculations similar to those used for preparation of ' $O$ ' antisera. All antigens and antisera were kept at $4{ }^{\circ}$, the latter with a few crystals of Thiomersal B.P. (British Drug Houses, Poole, Dorset) added as preservative.

Conjugation of antisera with fluorescein isothiocyanate. In a previous work (Hobson \& Mann, 1957) conjugation of antisera with fluorescein isocyanate was used. As this procedure is somewhat long, involving the preparation of the isocyanate from fluorescein amine, in these studies conjugation with fluorescein isothiocyanate was used as this compound is commercially available. Using rumen contents, which contain fluorescing material of a number of colours, and under our conditions of viewing, we find that the green fluorescence of fluorescein is easier to distinguish than the red-orange fluorescence of dyes such as RB 200 (Chadwick, McEntegart \& Nairn, 1958). The fluorescein isothiocyanate was obtained from British Drug Houses. The material as obtained appears to be impure and probably contains fluorescein amine, as it is a brownish yellow colour and not completely soluble in acetone. No attempt was made to purify the material, but, in so far as it was 
possible, an excess amount of isothiocyanate dissolved in acetone was used for conjugation. Some preliminary conjugations established that, under the conditions described below, this resulted in a conjugate of sufficient fluorescence. The procedure is a modified form of that of Marshall, Eveland \& Smith (1958). Whole serum, $2.5 \mathrm{ml}$., was stirred with $4.2 \mathrm{ml}$. $0.15 \mathrm{M}-\mathrm{NaCl}$, and $1.7 \mathrm{ml}$. 0.5 M-carbonate/bicarbonate buffer, $\mathrm{pH} \mathbf{9 \cdot 2}$, at $\mathbf{2}^{\circ}$ in a cold room. One millilitre of an acetone solution containing $20 \mathrm{mg}$. fluorescein isothiocyanate was added dropwise to the stirred serum solution from a hypodermic syringe fitted with a fine needle. After addition of the fluorescein solution the whole was left to stir at $2^{\circ}$ for $18 \mathrm{hr}$. The resultant fluorescent solution was dialysed at $2^{\circ}$ against 11 . volumes of $0.15 \mathrm{M}-\mathrm{NaCl}$ buffered to $\mathrm{pH} \mathrm{7.0}$ with $0.01 \mathrm{M}$-phosphate changed daily until the saline showed no further fluorescence in ultraviolet (UV) light. The dialysed solutions were then cleared by centrifuging at $22000 \mathrm{~g}$ at $0^{\circ}$ for $35 \mathrm{~min}$. and the supernatants stored at $4^{\circ}$ after the addition of a small amount of thiomersal. In the following descriptions 'conjugated antiserum' refers to the solution of antiserum in saline produced in this way. The conjugated antisera were then absorbed by shaking with liver powder as previously described (Hobson \& Mann, 1957). For absorption of $17 \mathrm{H}$ conjugated antiserum with Veillonella gazogenes about $1.5 \mathrm{ml}$. of the antiserum was treated twice at $38^{\circ}$ for $30 \mathrm{~min}$. with a few drops of a thick saline suspension of the bacteria, and centrifuged at $22000 \mathrm{~g}$ between each treatment and twice afterwards. Testing with a slide of $V$. gazogenes after this showed no reaction, but the reaction with the homologous organism remained.

Preparation of specimens. The slides used were of UV-transmitting glass (Shandon Scientific Co., Cromwell Place, London, S.W. 7) with Chance no. 1 coverslips. Immersion oil was Reichert non-fluorescing oil (Shandon Scientific Co.). Photographs were made on Ilford FP3 film with exposures of about 2-3 min. for UV and about 20 sec. for white light. (This light was of low intensity.) The microscope used was that described previously (Hobson \& Mann, 1957). In the previous work (Hobson \& Mann, 1957) wet preparations were used, as the methods of fixing tried all seemed to lead to increased non-specific fluorescence. However, the following method was finally used and this gives preparations which show no non-specific fluorescence of feedstuffs or protozoal contents when liver-absorbed sera are used and which remain stable for many months and can be examined many times. A thin smear of the bacteria or rumen contents was spread on a slide, any 'large' pieces of grass, etc., in the rumen contents being removed with a wire, and the film was allowed to dry at room temperature. The smear was then fixed by immersion in acetone for $20 \mathrm{~min}$., the acetone allowed to evaporate and the slide immersed in buffered saline (as used for dialysis) for 1-2 min. The excess saline was removed by blotting gently and a small drop of the conjugated antiserum spread over the damp smear and the slide incubated at $38^{\circ}$ for 30 min. in a Petri dish containing a piece of damp cotton wool to prevent evaporation. After this the slide was immersed in buffered saline for a few moments to remove excess antiserum, and washed by immersion in three lots of buffered saline for 3-5 min. each. The slide was gently blotted and a drop of redistilled glycerol containing about $10 \%(\mathrm{v} / \mathrm{v})$ buffered saline spotted on to the damp smear. This was covered by a cover glass and blotted as thin as possible. After examination, if the slide were to be kept, the excess immersion oil was removed by gentle wiping with a piece of tissue as the oil tends to become fluo- 
rescent on exposure to air. Although the glycerol provides a non-fluorescent mountant a drawback is that it reduces the contrast in white light and so does not give sharp photographs.

Sheep and sampling procedures. Sheep 30 was fed on $900 \mathrm{~g}$. hay and $450 \mathrm{~g}$. grass cubes per day given in two feeds. This is the same diet as the sheep from which Selenomonas ruminantium strain 17 was obtained. Sheep 4.3 was fed on 900 g. hay and $450 \mathrm{~g}$. concentrates (ground maize, crushed oats, bran) which is a similar diet to the sheep from which strain 6 was isolated. Samples were taken via a rumen cannula about $3 \mathrm{hr}$. after feeding.

\section{RESULTS}

Non-conjugated antisera. The antisera to Selenomonas ruminantium var. lactilyticas strains 6 and 17 were tested against the antigen suspensions prepared for ' $H$ ' and ' $\mathrm{O}$ ' agglutinations. ' $\mathrm{O}$ ' agglutination was recorded after $24 \mathrm{hr}$. at $50^{\circ}$, ' $\mathrm{H}$ ' agglutination after $4 \mathrm{hr}$. at $50^{\circ}$. The ' $O$ ' antisera reacted to a titre of $1 / 2560$ with the ' $O$ ' suspensions of the homologous organisms and the ' $H$ ' antisera reacted to a titre of $1 / 10240$ in the case of strain 6 and to $1 / 5120$ in the case of strain 17. It proved impossible, even by utilizing such techniques as the 'Craigie' tube, to obtain an inoculum which gave rise to a culture containing anything near $100 \%$ motile, flagellated, bacteria and so the ' $H$ ' antisera always contained a high proportion of ' $O$ ' antibodies. The ' $O$ ' reaction could be decreased by absorption of the antisera, but never eliminated, and so there was cross-reaction between ' $H$ ' and ' $O$ ' antisera and suspensions. However, there was some indication that the ' $H$ ' antigens were specific to the strains, and that the ' $O$ ' antigen might be specific for $S$. ruminantium var. lactilyticas, as an agglutination reaction was obtained with ' $O$ ' suspensions of the bovine rumen strain of $S$. ruminantium var. lactilyticas but not with the bovine strain of $S$. ruminantium.

Conjugated antisera. The conjugated antisera were tested against organisms in dried films prepared as under 'Methods'. The results with the non-conjugated antisera mentioned above, although not particularly clear cut with respect to ' $H$ ' and ' $\mathrm{O}$ ' agglutination, did show that antisera of sufficiently high titre for conjugation could be obtained and that these might be used for testing for the selenomonads in rumen contents. The $6 \mathrm{O}, 6 \mathrm{H}, 17 \mathrm{O}$ and $17 \mathrm{H}$ antisera were conjugated and liver absorbed as described above. Each of these antisera when tested against the corresponding antigen gave a good reaction, the ' $\mathrm{H}$ ' antisera seeming to give a somewhat brighter reaction with the cell walls than the ' $O$ ' antisera, with many flagella reacting in the ' $H$ ' suspensions. The flagella could easily be seen on visual examination but were too small to be photographed successfully. Some flagellated cells were also seen in the ' $O$ ' suspensions. The ' $H$ ' sera also reacted when tested with the ' $O$ ' suspensions of the corresponding bacteria and vice versa. All four conjugated antisera were tested against suspensions of Gram-negative coccus LC (Peptostreptococcus elsdenii) (Hobson, Mann \& Oxford, 1958); a rumen Streptococcus bovis (strain 18 C6, Hobson \& Mann, 1955); Sarcina bakeri (Mann, Masson \& Oxford, 1954); a bovine rumen strain of Ruminococcus albus; a sheep rumen Butyrivibrio strain; Bacteroides amylogenes (Doetsch, Howard, Mann \& Oxford, 1957) and a sheep rumen strain of Veillonella gazogenes (Hobson, Mann \& Oxford, 1958). Some reaction was seen with a proportion (perhaps $60 \%$ ) of the cells of Sarcina bakeri and 
a very faint reaction with a small proportion (perhaps $10 \%$ ) of the cells of the Butyrivibrio, but the only bright reaction, involving all cells, was with $V$. gazogenes. At the same time slides of rumen contents from sheep 30 and 43 were tested with all the antisera. These slides showed no non-specific reaction with food particles or protozoa, but some of the large selenomonads in the fields reacted well. In addition, in all cases a reaction with some small cocci and very occasionally some larger cocci was observed. No other bacteria reacted with the antisera. Since the reactions with rumen contents and individual bacteria both showed an apparently similar crossreaction and all the conjugated antisera behaved similarly, $17 \mathrm{H}$ antiserum was absorbed with $V$. gazogenes until no fluorescent reaction was obtained. This antiserum still reacted well with the corresponding 17 cells. When tested with rumen contents no reaction was observed other than with some selenomonad-like organisms. This absorbed antiserum was also tested against some other cultures of rumen bacteria which were available, including a lipolytic bacterium (Hobson \& Mann, 1961) and no cross-reactions were found. Some photographs of this antiserum and 170 antiserum reacting with selenomonads in rumen contents are shown in Pl. 1. A conjugated normal rabbit serum absorbed with liver powder did not react with anything in rumen contents. The $17 \mathrm{H}$ serum absorbed with $V$. gazogenes was further absorbed with thick suspensions of $17 \mathrm{H}$ and $17 \mathrm{O}$ antigens until no reaction was obtained with 17 cells. No reacting selenomonads were seen in films of sheep 43 rumen contents treated with this serum.

\section{DISCUSSION}

In some of the fields examined a few reacting organisms were seen which appeared to be more coccoid, or straighter, than the normal crescentic selenomonad shape. A comparison of these fields with many fields of pure cultures of selenomonads reacting with fluorescent antisera made it seem most likely that these were actually selenomonads turned 'end on' or 'sideways' to the viewer. The tests of the antisera with pure cultures and rumen contents show that the antisera seem to be specific for certain selenomonads (not all selenomonads in the rumen contents reacted with the antisera), possibly those of the variety lactilyticas. Although the large selenomonads (up to about $8 \mu$ long) were the most obvious cells reacting some of the reacting cells were considerably smaller, but not as small as the pure cultures. The evidence would thus suggest that the small selenomonads grown in pure culture are actually the large selenomonads seen in the rumen, and that even in the rumen there is some variation in size amongst serologically similar groups of selenomonads. No reaction in rumen contents was noted with anything resembling 'Quin's organism', a large bacterium which has occasionally been suggested to be a form of the selenomonads. This organism has not yet been cultured.

\section{REFERENCES}

Bryant, M. P. (1956). The characteristics of strains of Selenomonas isolated from bovine rumen contents. J. Bact. $72,162$.

Chadwick, C. S., McEntegart, M. G. \& Nairn, R. C. (1958). Fluorescent protein tracers : simple alternative to fluorescein. Lancet, $1,412$.

Doetsch, R. N., Howard, B. H., Mann, S. O. \& Oxford, A. E. (1957). Physiological factors in the production of an iodophilic polysaccharide from pentose by a sheep rumen bacterium. J. gen. Microbiol. 16, 156. 
Herbert, D. (1958). Some principles of continuous culture, in Recent Progress in Microbiology. Symp. $7^{\text {th }}$ int. Congr. Microbiol. p. 381

Hobson, P. N. \& Manv, S. O. (1955). Some factors affecting the formation of iodophilic polysaccharide in Group D streptococci from the rumen. J. gen. Microbiol. 13, 420.

Hobson, P. N. \& MaNN, S. O. (1957). Some studies on the identification of rumen bacteria with fluorescent antibodies. J. gen. Microbiol. 16, 463.

Hobson, P. N. \& MANN, S. O. (1961). The isolation of glycerol-fermenting and lipolytic bacteria from the rumen of the sheep. J. gen. Microbiol. 25, 227.

Hobson, P. N., ManN, S. O. \& Oxford, A. E. (1958). Some studies on the occurrence and properties of a large Gram-negative coccus from the rumen. J. gen. Microbiol. 19, 462.

Mann, S. O., Masson, F. M. \& OxFord, A. E. (1954). Facultative anaerobic bacteria from the sheep rumen. J. gen. Microbiol. 10, 142.

Marshall, J. D., Eveland, W. C. \& SMrTh, C. W. (1958). Superiority of fluorescein isothiocyanate (Riggs) for fluorescent-antibody technic with a modification of its application. Proc. Soc. exp. Biol., N.Y. 98, 898.

Morr, R. J. \& Masson, M. J. (1952). An illustrated scheme for the microscopic identification of the rumen micro-organisms of sheep. J. Path. Bact. 64, 343.

\section{EXPLANATION OF PLATE}

Plate 1

All photographs were of dry film preparations. Magnification in all cases $\times 880$.

Fig. 1. Selenomonad in rumen contents of sheep 43 reacting with 17 ' $H$ ' antiserum.

Fig. 2. Same field as fig. 1 in white light.

Fig. 3. Larger selenomonad in rumen contents of sheep 30 reacting with 17 ' $O$ ' antiserum.

Fig. 4. Same field as fig. 3 in white light.

Fig. 5. Large selenomonad in rumen contents of sheep 30 reacting with 17 ' $O$ ' antiserum. The two large objects are plant material fluorescing bright blue-white.

Fig. 6. Same field as fig. 5 in white light.

Fig. 7. Large selenomonad in rumen contents of sheep 30 reacting with 17 ' $O$ ' antiserum. General background of blue-white fluorescing plant debris, and slight blue autofluorescence from some bacteria, e.g. the oscillospira in the top left.

Fig. 8. Same field as fig. 7 in white light. 
Journal of General Microbiology, Vol. 29, No. 2

Plate 1

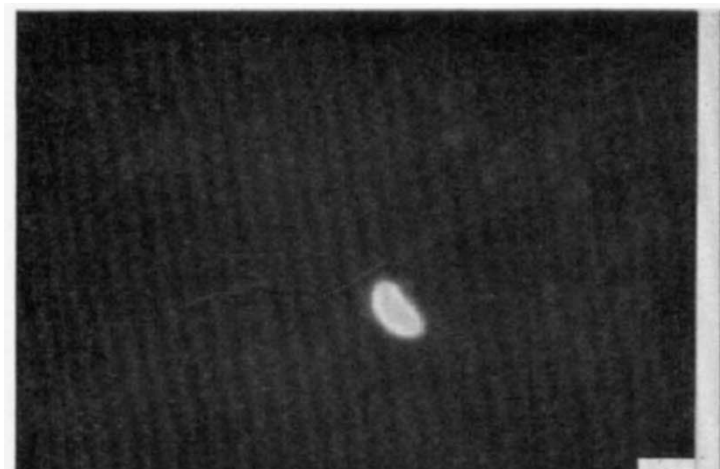

1

